\title{
Erratum to: Fatal breast cancer risk in relation to use of unopposed estrogen and combined hormone therapy
}

\author{
Gaia Pocobelli • Polly A. Newcomb • \\ Christopher I. Li $\cdot$ Linda S. Cook • \\ William E. Barlow $\cdot$ Noel S. Weiss
}

Published online: 6 May 2014

(C) Springer Science+Business Media New York 2014

\section{Erratum to: Breast Cancer Res Treat \\ DOI 10.1007/s10549-014-2911-0}

Unfortunately, in the original publication of the article, the funding information has been missed out inadvertently. The funding information is given below.
This work was supported by the National Cancer Institute at the National Institutes of Health (Grants R03CA135700 and K05CA092002 to N.S.W., and Grant K05CA152715 to P.A.N.).

The online version of the original article can be found under doi:10.1007/s10549-014-2911-0.

G. Pocobelli · P. A. Newcomb - C. I. Li · N. S. Weiss

Department of Epidemiology, University of Washington, Seattle,

WA, USA

G. Pocobelli $(\bowtie) \cdot$ W. E. Barlow

Group Health Research Institute, 1730 Minor Avenue, Suite 1600, Seattle, WA 98101, USA

e-mail: gpocobel@uw.edu

\section{P. A. Newcomb - C. I. Li · N. S. Weiss}

Public Health Sciences Division, Fred Hutchinson Cancer

Research Center, Seattle, WA, USA

L. S. Cook

Division of Epidemiology and Biostatistics, Department of Internal Medicine, University of New Mexico, Albuquerque,

NM, USA

W. E. Barlow

Department of Biostatistics, University of Washington, Seattle,

WA, USA

W. E. Barlow

Cancer Research and Biostatistics, Seattle, WA, USA 